\title{
Parameters as Third Factor Timing Optionality
}

\author{
Miki Obata ${ }^{1}$, Marlyse Baptista ${ }^{2}$ and Samuel Epstein ${ }^{2}$ \\ Mie University ${ }^{1}$ and University of Michigan, Ann Arbor $^{2}$
}

\section{Framing the Issues}

The main goals of this research are to illustrate explanatory weaknesses of postulating parameters of UG and how, within Third Factor Minimalism, parameters might be not only described but explained in terms of the third-factor (not UG-specific) concept of optimal computation. Here, we present a case study of crosslinguistic variation between English and Kilega.

In the GB theory, linguistic representations are constructed under the virtually "rule-free" Move-alpha representational approach. This approach enables the computational system to build representations freely. If descriptively adequate, at the D-structure, S-structure, and LF levels various filters on representation exclude unwanted representations and only the well-formed ones survive. Those filters are regarded as specific to the human language faculty in this framework, with parametric values describing crosslinguistic syntactic variation in I-languages.

In minimalism, on the other hand, linguistic representations are derived by iterative application of the single well-defined rule Merge, (the derivational approach) subject to third factor constraints. Each step of the derivation is constrained by hypothesized principles of computational efficiency. In contrast to specific UG-specific constraints postulated in the GB theory, Chomsky $(1965,2005)$ argues that the derivational constraints that can by hypothesis be reduced to general, third factor efficiency constraints are not parameterizable, since third factor constraints by definition constrain all computation hence all linguistic computation. In other words, parameters specific to the language faculty can no longer be invoked since third factor principles are not specific to the faculty of language. If so, however, the problem is that linguistic variation which has been described by appeal to parametric values would appear to be rendered indescribable.

Under the minimalist 3rd factor derivational approach, we argue that some cross-linguistic syntactic variation concerns the relative ordering of universal rules (much in the spirit of Huang's (1982) pathbreaking analysis couched within GB theory). Differing orders are 'minimalistically' allowed only when each order satisfies optimal computation (=a "tie" for first place among $>1$ derivation). With respect to the derivational ordering view, Chomsky (1991, 2008), Boeckx (2008) and Richards (2008) propose that third factor computational efficiency might well express points of underspecification allowing optimal computation to be executed in more than one way, thus accounting for variation without appeal to language specific parameters of UG (See also Epstein et al 1998, as discussed in Richards 2008, for an analysis consistent with this approach.) That is, third factor underspecification may well replace a theory in which crosslinguistic variation is expressed by stipulated language-specific parameters of UG with one in which crosslinguistic variation is deduced from third factor computational efficiency allowing more than one optimal solution.

In this work, we provide a case-study suggesting that some crosslinguistic variations consistent with this current formulation of minimalist analysis can be explained by appeal to the existence of (equally optimal) variations in the timing of application of universal operations, without appeal to descriptive parameters of UG. In the particular case we examine here, the relative timing of: (i) feature-inheritance (Chomsky 2007) and (ii) wh-movement is subject to crosslinguistic variation. More concretely, we demonstrate that the following timing difference explains agreement variations observed in English vs. Kilega 
wh-movement phenomena: In English, the order of applying operations is: [1] wh-movement, [2] feature-inheritance, [3] T-agreement. In Kilega, on the other hand, the order is: [1] feature-inheritance, [2] T-agreement, [3] wh-movement. If our analysis is on track, at least some I-language variation can be explained by optimal computation being executable in more than one way.

\section{Timing of Derivation: Feature-Inheritance and T-Agreement}

Chomsky (2007) proposes that $\mathrm{T}$ inherits phi-features from C (i.e. feature-inheritance). If a sentence involves wh-movement, timing of feature-inheritance plays a crucial role. Consider the following sentences:
a. Which dogs am I seeing?
b. $\quad$ *Which dogs are I seeing?

In (1a), T agrees with the subject "I", so that the verb is inflected from "be" to "am". In (1b), on the other hand, T agrees with the fronted object "which dogs", so that the verb is inflected from "be" to "are". (1b) is ungrammatical. What do these phenomena (presumably representative of an infinite number of cases known by speakers of English) imply? It tells us about the relative ordering of feature-inheritance and wh-movement (Internal Merge). In English, feature-inheritance follows successive-cyclic wh-movement, (as we will show, below, Kilega I-languages exhibit the opposite order, i.e. feature-inheritance follows successive-cyclic wh-movement.)

Consider again, (1a). It is derived as follows:

$$
\begin{aligned}
& \text { Feature-inheritance follows wh-movement to Edge-CP. } \\
& \text { [СР which dogs } \mathrm{C}_{\text {[phi] }}[\mathrm{TP} \mathrm{T}[\mathrm{vP}<\text { which dogs }>\text { [vP I v [vP ... } \\
& \text { [1] wh-movement [2] feature-inheritance [3] T-agreement } \rightarrow \text { (1a) }
\end{aligned}
$$

ONLY after phi-features are inherited by T from C (Chomsky 2007), can T probe, Match and Agree. Here, the object undergoes Internal Merge to Edge-CP before T-to-C phi-feature inheritance and Agree takes place as illustrated in (2), i.e. T, still lacking phi-features, does not yet have the ability to Agree. Crucially, "which dogs" is no longer a potential agreement goal for $\mathrm{T}$ i.e. informally, by the time $\mathrm{T}$ receives phi-features from $\mathrm{C}$, the wh-phrase has moved out of the c-command domain of T: the subject "I" is therefore the closest Goal at this time. T agrees with the subject "I" in this configuration. Thus, in English, feature-inheritance takes place ONLY after the shifted object wh-phrase has moved out of the c-command domain of T, 'forcing' T-agreement with the subject, under Minimal Search.

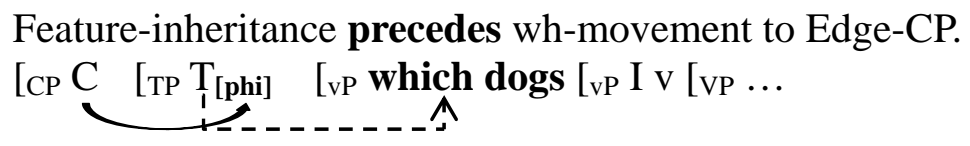

[1] feature-inheritance [2] T-agreement [3] wh-movement

$\rightarrow(1 \mathrm{~b})$

On the other hand, agreement between $\mathrm{T}$ and the shifted object wh-phrase (which dogs) is (for English, overgenerated) by fronting the object wh-phrase to outer edge edge-vP ("object shift"), so it is closer to T than the subject "I" is. In this configuration, T agrees with "which dogs" by minimal search as in (3) since feature-inheritance precedes wh-movement to Edge-CP. As a result, $\mathrm{T}$ is inflected from "be" to "are" and the ungrammatical (1b) is overgenerated. 
Is there any language which takes the reverse order to English, thereby forcing agreement with a shifted object wh-phrase as in the ungrammatical (1b)? In fact, T in Kilega agrees with the moved object wh-phrase, (not the subject), which adopts the 'reverse' rule order to English. Kilega, which is a Bantu language, allows both overt wh-fronting $(\rightarrow 4 \mathrm{a})$ and wh-in-situ $(\rightarrow 4 b)$.
Kilega object wh-movement; T agrees with shifted wh-object
a. Bíkí bi-á-kás-íl-é bábo bíkulu mwámí mu-mwílo? 8what 8CA-A-give-PERF-FV 2that 2woman 1chef 18-3village 'What did those women give the chief in the village?'
b. Bábo bíkulu b-á-kás-íl-é mwámí bíkí mu-mwílo? 2that 2women 2SA-A-give-PERF-FV 1chief 8what 18-3village 'What did those women give the chief in the village?'

(Carstens, 2005: 220)

In (4a), T (ultimately, by "affix hopping” onto the verb) agrees with the fronted wh-phraseboth elements obligatorily bear the noun class number 8. (The verb in (4a) then moves to C, so that it also bears the C-agreement morpheme CA). In Kilega, that is, T agrees with the fronted object wh-phrase, not the subject, unlike in English. If the wh-phrase stays in-situ as in (4b), T agrees with the subject "women", so that both elements share the noun class number 2. Kilega shows the opposite behavior to English with respect to T-agreement in object wh-movement.

Must we DESCRIBE the difference by postulating a descriptive Parameter of UG such as English: [+ subject agreement] vs. Kilega: [+ object agreement], basically describing the variation we seek to explain? We think the answer is NO. These variant rule orders are predicted to be possible by a theory of third factor underspecification. That is, "computationally efficient satisfaction of the interfaces" (= the strong minimalist thesis) requires all the operations to apply. However, the order in which they apply is not specified. Hence it is predicted by this theory that precisely here there are rule-ordering options. The proposed analysis demonstrates that the timing difference of feature-inheritance, agreement and wh-movement explains the variations in T-agreement between English and Kilega without a stipulated agreement parameter as part of UG.

\section{Conclusion}

This research has pursued the problem of how parameters can be re-interpreted in the form observing the third-factor (not UG-specific) concept of optimal computation. As a case study, we specifically discuss the derivational timing between feature-inheritance and wh-movement in English and Kilega. Valuation of Case and phi-features is required for CI-convergence as is Feature Transfer from C to T (deducibly required (see Richards 2007)) Valuation must be computed optimally. Feature-inheritance, agree and wh-movement must ALL apply. The order in which they apply is irrelevant. Either order yields convergence in 3 operations = efficient computation. If the proposed analysis is on track, parametric variation, is at least in part deducible from third factor underspecification of rule ordering with respect to "computationally efficient satisfaction of interface conditions". 


\section{References}

Boeckx, Cedric. 2011. Approaching Parameters from Below. The Biolinguistic enterprise: New perspectives on the evolution and nature of the human language faculty, ed. by Cedric Boeckx and Anna-Maria Di Sciullo, Oxford: Oxford University Press.

Carstens, Vicky. 2005. Rethinking complementizer agreement: Agree with a Case-checked goal. Linguistic Inquiry 34, 393-412.

Chomsky, Noam. 1965. Aspects of the Theory of Syntax. Cambridge: MIT Press.

Chomsky, Noam. 1981. Lectures on Government and Binding. Dordrecht: Foris.

Chomsky, Noam. 1991. Some notes on economy of derivation and representation. Principles and Parameters in Comparative Grammar, ed. by Robert Freidin, 417-54. Cambridge: MIT Press.

Chomsky, Noam. 2005. Three factors in language design. Linguistic Inquiry 36, 1-22.

Chomsky, Noam. 2007. Approaching UG from below. Interfaces + Recursion = Language? ed. by Uli Sauerland and Hans-Martin Gärtner, 1-29, Berlin, Mouton de Gruyter.

Chomsky, Noam. 2008. On phases. Foundational Issues in Linguistic Theory: Essays in Honor of Jean-Roger Vergnaud, ed. by Robert Freidin, Carlos P. Otero and Maria Luisa Zubizarreta, 133-166, MIT Press, Cambridge, MA.

Epstein, Samuel, Erich Groat, Ruriko Kawashima and Hisatsugu Kitahara. 1998. A Derivational Approach to Syntactic Relations. Oxford: Oxford University Press.

Huang, James. 1982. Logical Relations in Chinese and the Theory of Grammar. Doctoral dissertation. MIT.

Richards, Marc. 2007. On feature inheritance: an argument from the phase impenetrability condition. Linguistic Inquiry 38, 563-572.

Richards, Marc. 2008. Two kinds of variation in a minimalist system. Varieties of Competition, ed. by Fabian Heck, Gereon Müller and Jochen Trommer, 133-162, University of Leipzig. 